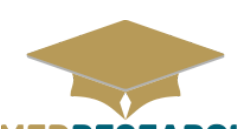

MEDRESEARCH

www.medresearch.in

\title{
Study on factors affecting complementary feeding practices in infants and young children in a rural area of Bihar
}

\author{
Kumar A. ${ }^{1}$, Kumar L. ${ }^{2 *}$, Kumar T. ${ }^{3}$, Roy C. ${ }^{4}$, Jha H. ${ }^{5}$, Kumar Lal P. \\ DOI: https://doi.org/10.17511/ijphr.2020.i1.01
}

\footnotetext{
${ }^{1}$ Akhilesh Kumar, Tutor, Department of PSM, Vardhman Institute of Medical sciences, Pawapuri, Bihar, India.

2* Laxman Kumar, Associate Professor, Department of PSM, Vardhman Institute of Medical sciences, Pawapuri, Bihar, India.

3 Tushar Kumar, Tutor, Department of PSM, Government Medical College, Bettiah, Bihar, India.

${ }^{4}$ Chittaranjan Roy, Professor, Department of PSM, Darbhanga Medical College, Darbhanga, Bihar, India.

5 Hem Kant Jha, Associate Professors, Department of PSM, Darbhanga Medical College, Darbhanga, Bihar, India.

6 Prabhat Kumar Lal, Associate Professors, Department of PSM, Darbhanga Medical College, Darbhanga, Bihar, India.
}

Introduction: Proper infant and young child feeding practices are essential for the prevention of childhood morbidity and mortality. NFHS-4 reported that about half of the children in Bihar are not receiving complementary foods timely. The present study was conducted to assess the factors affecting the complementary feeding of infants and young children. Methods: The present crosssectional study was conducted upon mothers/ caretakers of 400 children age 6-24 months. Sociodemographic details and complementary feeding practices were noted. Results: The mean age of initiation of complementary feeding was 5.2 months. Cereals were the most common complementary food given while only $19 \%$ of children received food from all the food groups. Half of the children $(50.8 \%)$ were given food of appropriate consistency and $41 \%$ were given the proper amount. 53.8\% were given marketed foods. A significant association was seen between ideal practices and type of family $(p=0.002)$, mother's education $(p=0.000)$, socioeconomic status $(p=0.000)$ and IYCF related advice given during immunization sessions $(p=0.000)$. Conclusion: Appropriate feeding practice is very low and effort should be made to increase the appropriate feeding practices.

Keywords: Complementary feeding, Cross-sectional study, Factors

Corresponding Author

Laxman Kumar, Associate Professor, Department of PSM, Vardhman Institute of Medical sciences, Pawapuri, Bihar, India.

Email: nalandahealthcare@gmail.com

\section{How to Cite this Article}

Kumar A, Kumar L, Kumar T, Roy C, Jha H, Lal PK. Study on factors affecting complementary feeding practices in infants and young children in a rural area of Bihar. Public Health Rev Int J Public Health Res. 2020;7(1):1-6.

Available From

https://publichealth.medresearch.in/index.php/ijphr/ article/view/131
To Browse

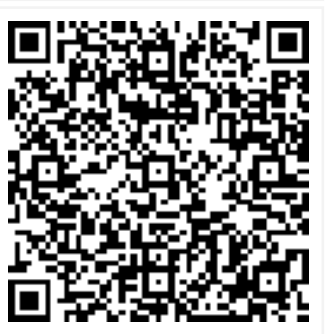

Manuscript Received 2020-01-10

Conflict of Interest No
Review Round 1 2020-01-20

Funding Nil
Review Round 2 2020-01-25

Ethical Approval Yes
Review Round 3

Plagiarism X-checker $7 \%$
Accepted 2020-02-01

Note

(c) 2020 by Akhilesh Kumar, Laxman Kumar, Tushar Kumar, Chittaranjan Roy, Hem Kant Jha, Prabhat Kumar Lal and Published by Siddharth Health Research and Social Welfare Society. This is an Open Access article licensed under a Creative Commons Attribution 4.0 International License https://creativecommons.org/licenses/by/4.0/ unported [CC BY 4.0] 


\section{Introduction}

Different reports have repeatedly emphasized the role of proper infant and young child feeding practices for prevention of childhood morbidity and mortality and ensuring adequate nutrition. Globally, one-third of the estimated 9.5 million deaths that occurred in 2006 in children less than five years of age were attributed directly or indirectly to undernutrition [1]. Infant and young child feeding (IYCF) practices recommend exclusive breastfeeding up to the age of six months; timely initiation of feeding solid, semisolid foods after six months onwards. It also recommends feeding small amounts, increasing the number of foods and frequency of feeding as the child gets older while maintaining breastfeeding as demanded by the child. In Bihar, the percentage of children who received complimentary food at 6-7 months of age increased from $31 \%$ in the NFHS-3 to $54 \%$ in the NFHS-4. Still, about half of the children are not receiving complementary foods timely [2]. Knowledge on feeding practices of infants and young children $\mathrm{n}$ is crucial for undertaking or improving health and nutrition programs in the country. Different studies have tried to explore the reasons behind improper complementary practices. Such studies have not been done in this area. Hence, this study was conducted.

\section{Aims and objectives}

The present study was conducted to assess the factors affecting complementary feeding of infant and young children, attending OPD of RHTC Kalyanpur attached to Darbhanga Medical College.

\section{Material and Methods}

Study setting: The present study was conducted at the Darbhanga Medical College, Darbhanga, Bihar. The rural training center of this institute covers a population of $3,27,653$ population with 3 additional $\mathrm{PHC}$ and 38 sub-centers under its jurisdiction. Large numbers of mothers with children from the PHC area attend OPD for immunization and treatment of illness. The staff nurse posted at this center has already been trained for IYCF.

Duration and type of study: The present study was conducted between Dec 2014 to Nov 2016. Data collection was done between March 2016 to Aug 2016.

Study subjects: Children of 6 to 24 months of age
Who attended the outpatient department of Primary health center, Kalyanpur were included. Mothers/caretakers of children were interviewed.

Inclusion criteria: Children aged 6 months to 24 months attending the OPD of Primary Health Centre, Kalyanpur were included in the present study.

Exclusion criteria: Children with known anomalies and who were very sick needing emergency care were excluded.

Sampling: The sample size was determined by using the formula: (Za)2pq/D2. $57.0 \%$ of children are fed according to a recommendation by IYCF in terms of foods from recommended food groups and are fed at least the recommended minimum number of times. Considering allowable error to be $5 \%$. Size of sample $=(1.96) 2 \mathrm{X} 0.57 \mathrm{X} 0.43 /(0.05) 2=376 . \mathrm{A}$ total of 400 study subjects were included. Systematic random sampling was used for data collection amongst the cases attending OPD.

Data collection procedure: A semi-structured questionnaire was used to collect the data with the mother. Before the data collection process, permission was taken from the hospital authority for the study. Mothers of consecutive children fulfilling the inclusion criteria were enrolled in the study until the required sample size was reached. Mothers were informed about the study and consent was taken. Then, data were collected by personal interview. Intern, staff-nurse and medical social worker (MSW) helped in data collection.

Data analysis: Data was entered in Microsoft Excel and Data was entered and analyzed using Medcalc software. Percentage, proportions, and contingency tables were used for the description of the data. Association of inappropriate feeding practices with socio-demographic characteristics was analyzed using the chi-square test. P-value $<0.05$ was considered as statistically significant.

Ethical consideration and permission: Approval from the Institutional Ethics Committee was obtained. Informed consent was taken from the patients. The confidentiality of records was maintained.

\section{Results}

A total of 400 mothers/ caretakers were interviewed in the present study. Table-1 shows the background characteristics of the study population. $62.5 \%$ of children were males, $63.3 \%$ of them belonged to the nuclear family, $93 \%$ of them were Hindus. The 
Mean age of children was 12.9 months. $19 \%$ of mothers were illiterate and $70 \%$ of them were housewives.

Table-1: showing background characteristics of the study population

\begin{tabular}{|c|c|c|c|}
\hline Background characteristics & Values & Frequency & $\%$ \\
\hline Age (in months) & - & \multicolumn{2}{|l|}{$12.9 \pm 5.2$} \\
\hline \multirow[t]{2}{*}{ Sex } & Male & 250 & 62.5 \\
\hline & Female & 150 & 37.5 \\
\hline \multirow[t]{2}{*}{ Type of family } & Nuclear & 253 & 63.3 \\
\hline & Joint & 147 & 36.7 \\
\hline \multirow[t]{5}{*}{ Mother's education } & Illiterate & 76 & 19 \\
\hline & Primary & 60 & 15 \\
\hline & Secondary & 124 & 31 \\
\hline & Intermediate & 100 & 25 \\
\hline & Bachelor and above & 40 & 10 \\
\hline \multirow[t]{5}{*}{ Mother's occupation } & Housewife & 280 & 70 \\
\hline & Agriculture & 60 & 15 \\
\hline & Business & 24 & 6 \\
\hline & Service & 24 & 6 \\
\hline & Skilled work & 12 & 3 \\
\hline \multirow[t]{5}{*}{ Socioeconomic status } & A & 68 & 16.5 \\
\hline & B & 25 & 6.3 \\
\hline & C & 179 & 44.8 \\
\hline & D & 112 & 28 \\
\hline & E & 16 & 4 \\
\hline \multirow[t]{2}{*}{ Religion } & Hindu & 372 & 93 \\
\hline & Muslim & 28 & 7 \\
\hline
\end{tabular}

Table-2 shows awareness of mothers regarding complementary feeding. $88 \%$ of mothers knew when to start complementary feeding, $87.8 \%$ knew what foods to give but only $36.8 \%$ were aware of the correct frequency.

Table-2: showing awareness of mothers regarding complementary feeding

\begin{tabular}{|l|l|l|l|}
\hline \multicolumn{1}{|c|}{ Characteristics } & Values & Frequency & $\%$ \\
\hline \multirow{3}{*}{ When to start complementary feeding } & Yes & 352 & 88 \\
\cline { 2 - 4 } & No & 48 & 12 \\
\hline \multirow{2}{*}{ What foods to be given } & Yes & 351 & 87.8 \\
\cline { 2 - 4 } & No & 49 & 12.2 \\
\hline Correct frequency & Yes & 147 & 36.8 \\
\cline { 2 - 4 } & No & 253 & 63.2 \\
\hline
\end{tabular}

Table-3 shows the complementary feeding practices. The mean age of initiation of complementary feeding was 5.2 months. Cereals were the most common complementary food given while only $19 \%$ of children received food from all the food groups. Half of the children (50.8\%) were given food of appropriate consistency and $41 \%$ were given the proper amount. $53.8 \%$ were given
Table-3: Showing complementary feeding practices

\begin{tabular}{|c|c|c|c|}
\hline Characteristics & Values & |Frequency & $\%$ \\
\hline $\begin{array}{l}\text { Age at initiation of complementary } \\
\text { feeding (in months) }\end{array}$ & & $5.2 \pm 1.6$ & \\
\hline \multirow[t]{7}{*}{ Types of complementary foods given } & Cereals & 112 & 28 \\
\hline & Milk product & 28 & 7 \\
\hline & Cerelac & 32 & 8 \\
\hline & $\begin{array}{l}\text { Vegetables and } \\
\text { fruits }\end{array}$ & 100 & 25 \\
\hline & $\begin{array}{l}\text { Egg, meat or } \\
\text { fish }\end{array}$ & 20 & 5 \\
\hline & Pulses & 32 & 8 \\
\hline & All & 76 & 19 \\
\hline \multirow[t]{2}{*}{ Amount of complementary foods given } & Inappropriate & 236 & 59 \\
\hline & Appropriate & 164 & 41 \\
\hline \multirow{3}{*}{$\begin{array}{l}\text { Consistency of complementary foods } \\
\text { given }\end{array}$} & Thick & 124 & 31 \\
\hline & Thin & 73 & 18.2 \\
\hline & Appropriate & 203 & 50.8 \\
\hline \multirow[t]{2}{*}{ Separate container used } & Yes & 268 & 67 \\
\hline & No & 132 & 33 \\
\hline \multirow[t]{2}{*}{ Use of marketed foods } & Yes & 215 & 53.8 \\
\hline & No & 185 & 46.2 \\
\hline
\end{tabular}

Table-4: Showing association between background factors and complementary feeding

\begin{tabular}{|c|c|c|c|c|}
\hline Characteristics & Values & $\begin{array}{l}\text { Not ideal } \\
\text { practice }\end{array}$ & $\mid \begin{array}{c}\text { Ideal } \\
\text { practice }\end{array}$ & | Significance \\
\hline \multirow[t]{2}{*}{ Type of family } & Nuclear & 222 & 31 & \multirow{2}{*}{$\begin{array}{l}X 2=9.9843 \\
p=0.00157\end{array}$} \\
\hline & Joint & 111 & 36 & \\
\hline \multirow[t]{5}{*}{ Mother's education } & IIlliterate & 69 & 7 & \multirow{5}{*}{$\begin{array}{l}X 2=39.1685 \\
p=0.00001\end{array}$} \\
\hline & Primary & 52 & 8 & \\
\hline & Secondary & 111 & 13 & \\
\hline & Intermediat & 81 & 19 & \\
\hline & $\begin{array}{l}\text { Bachelor } \\
\text { and above }\end{array}$ & 20 & 20 & \\
\hline \multirow[t]{5}{*}{ Mother's occupation } & Housewife & 232 & 48 & \multirow{5}{*}{$\begin{array}{l}X 2=5.5416 p= \\
0.23609\end{array}$} \\
\hline & Agriculture & 54 & 6 & \\
\hline & Business & 19 & 5 & \\
\hline & Service & 11 & 1 & \\
\hline & Skilled work & 17 & 7 & \\
\hline \multirow[t]{5}{*}{ Socio-economic status } & A & 59 & 9 & \multirow{5}{*}{$\begin{array}{l}X 2=43.980 \\
p=0.00001\end{array}$} \\
\hline & $B$ & 21 & 4 & \\
\hline & C & 168 & 11 & \\
\hline & $\mathrm{D}$ & 72 & 40 & \\
\hline & $E$ & 13 & 3 & \\
\hline \multirow{2}{*}{\begin{tabular}{|l} 
Advice received during \\
immunization
\end{tabular}} & Yes & 106 & 56 & \multirow{2}{*}{$\begin{array}{l}X 2=61.9886 \\
p<0.00001\end{array}$} \\
\hline & No & 227 & 11 & \\
\hline
\end{tabular}

Table-4 shows the association between background 
Factors and complementary feeding. A significant association was seen between ideal practices and type of family $(p=0.002)$, mother's education $(p=0.000)$, socioeconomic status $(p=0.000)$ and IYCF related advice given during immunization sessions $(p=0.000)$.

\section{Discussion}

Infant and young child feeding practices include early initiation of breastfeeding within one hour of life, no bottle feeding and exclusive breastfeeding thereafter up-to 6 months and timely introduction of solid/semi-solid foods from the age of six months increasing in amount and frequency over time along with breastfeeding as demanded by the child $[3,4]$. The National family health survey 2015-16 has shown that IYCF practices are still low in India.

Only $30.7 \%$ of the children are fed according to the IYCF practices; that is feeding milk and milk products and food items from the recommended food groups and at the minimum recommended frequency [2]. Hence, the present study explored the factors influencing the appropriateness of complementary feeding, to assess the knowledge of mothers regarding complementary feeding and to evaluate the practices of complementary feeding in terms of quantity, quality, and timing.

A total of 400 mothers/ caretakers were interviewed in the present study. The mean age of children was 12.9 months. $62.5 \%$ of them were males, $63.3 \%$ belonged to the nuclear family and $93 \%$ were Hindus. $19 \%$ of mothers were illiterate and $70 \%$ of them were housewives. Javalkar et al found that $49.5 \%$ of mothers were Hindus, $43.4 \%$ were Muslims and $7.1 \%$ belonged to Christian and other religions. There were $35.1 \%$ of women educated till secondary school, with only $5.1 \%$ illiterate. The majority of the women (78.2\%) were housewives and only $21.8 \%$ of them were employed and contributing to the family income among them.

A majority (83.8\%) of them belonged to socioeconomic classes II and III, according to Modified BG Prasad's Socioeconomic Classification. The majority of the mothers $(66.9 \%)$ belonged to nuclear families, $18.4 \%$ belonged to joint families, and only $4.5 \%$ belonging to Three generation family [5]. Rao et al observed that the majority of children (41\%) belonged to the 6-12 months age group, $56.5 \%$ were male children and $52 \%$ belonged to a joint family. Most of the mothers (81\%) were homemakers [6].
$88 \%$ of mothers knew when to start complementary feeding, $87.8 \%$ knew what foods to give but only $36.8 \%$ were aware of the correct frequency. The mean age of initiation of complementary feeding was 5.2 months. Cereals were the most common complementary food given while only $19 \%$ of children received food from all the food groups. Half of the children (50.8\%) were given food of appropriate consistency and $41 \%$ were given the proper amount. $53.8 \%$ were given marketed foods. Javalkar et al reported that $69.3 \%$ of mothers in the rural area and $30.6 \%$ of mothers in the urban area started complementary feeds at the age of 6 months. 35.2\% started complementary feeds before 6 months of age; the most common reason for starting the complementary feeds before 6 months of age was advice by family members/friends followed by the belief that breast milk alone is not sufficient for the child. The most common complementary food given first was rice and dal cooked together by $29.2 \%$ mothers followed by readymade baby feeds (20\%). The number of meals per day given to the child varied from 2-4/day, both in an urban and rural area [5].

Yadav et al found in the urban and rural areas of Bihar that $17.70 \%$ urban and $13.10 \%$ rural mothers started complementary foods before 6 months of age, the reason for early weaning being mothers felt that breast milk was not sufficient. The most common food given first as weaning food both in urban as well as rural areas was rice [7]. Rao et al found that $77.5 \%$ of mothers had started complementary feeding at the recommended time and $12 \%$ of children had delayed complementary feeding. The most common reason given for the delayed introduction of complementary feed was that mothers felt their milk was enough for baby. Only $32 \%$ of mothers practiced the adequate quantity of complementary feeds. The majority $(82 \%)$ mothers had initiated weaning with homemade food. Around $22 \%$ of children were bottle-fed. Ragi, wheat, and rice were the most common homemade complementary food used [6].

A significant association was seen between ideal practices and type of family $(p=0.002)$, mother's education $(p=0.000)$, socioeconomic status $(p=0.000)$ and IYCF related advice given during immunization sessions $(p=0.000)$. Javalkar et al reported that statistical association between sociodemographic variables and initiation of complementary feeding was not significant in the rural area. However, in the urban area, 
Socioeconomic status had a significant association $(p<0.05)$ [5]. Rao et al also found in the univariate analysis that the practice of complementary feeding at the recommended time of six months was significantly associated with socioeconomic status $(p=0.036)$, birth order $(p=0.013)$, place of delivery (0.033), maternal education $(p=0.038)$ but not with the gender of the child, maternal age, maternal employment status, type of family and advice about complementary feeding during immunization [6].

Dhami et al analyzed NFHS-4 data and observed a wide variation in the prevalence of introduction of solid, semi-solid or soft foods (complementary foods) among infants aged 6-8 months in regional India; highest in the South $(61 \%)$ and lowest in the Central and Northern regions (38\%). Minimum dietary diversity (MDD) was highest in the South $(33 \%)$ and lowest in the Central region (12\%). The factors associated with complementary feeding practices also differed across Indian regions.

Significant modifiable factors associated with complementary feeding practices included higher household wealth index for the introduction of complementary foods in the North and Eastern India; higher maternal education for MMF and MDD in the North and Central regions; and frequent antenatal care visits ( $\geq 4$ visits) for all indicators but for different regions $[6,8]$.

\section{Limitations}

The present study was descriptive in nature and generates hypotheses only. An analytical study is needed to test the hypothesis and calculate the risk. It covered a population of rural centers of $\mathrm{DMCH}$, Darbhanga. Studies covering a larger area are needed to generalize the findings.

\section{Conclusion}

It is seen in the present study that ideal feeding was practiced only in a minority of children. Some of the mothers used cereals as a weaning food but a few mothers knew the proper method of its preparation. The frequency of complementary feeding given to children was good in the majority of the children but its consistency and amount were found to be not appropriate as per recommendation by IYCF Guidelines in more than half of the children.

There was an association of appropriate feeding practices with mother's education, type of family, family income (SES) and feeding advice during
Immunization. The findings highlight the importance of the mother's education, profession and giving education in the immunization clinic for the infant and young child feeding.

Appropriate feeding practice is very low and effort should be made to increase the appropriate feeding practices by putting more effort inconsistency of food and timing of feeding. The immunization clinic is the best place and vaccination time is the ideal time for educating mothers about appropriate feeding practices.

\section{What does the study add to the existing knowledge}

This study gives insight into the factors associated with complementary feeding practices in infants and young children of Bihar.

\section{Author's contribution}

Dr. Akhilesh Kumar is the principal author and conducted this study. Dr. Laxman Kumar and Dr. Tushar Kumar reviewed the literature and assisted in finalizing the study design. This study was conducted under the supervision of Dr. Chittaranjan Roy who was the study guide. Dr. Hem Kant Jha edited this article and Dr. Prabhat Kumar Lal assisted in data analysis.

\section{Reference}

01. Black R. Maternal and child undernutritionglobal and regional exposures and health consequences. Lancet. 2008;371(9608)243260.

doi: [Article] [Crossref]

02. Goverment of India. State Fact Sheet Bihar. National Family Health Survey- 4. 2015-2016. Available at [Article] [Crossref]

03. Aggarwal A, Verma S, Faridi MMA, Dayachand. Complementary feeding- Reasons for inappropriateness in timing, quantity and consistency. Indian J Pediatr. 2008;75(1)49-53. doi: [Article] [Crossref]

04. Ahmad I, Khalique N, Khalil S, Urfi, Maroof M. Complementary feeding practices among children aged 6-23 months in Aligarh, Uttar Pradesh. J Family Med Prim Care. 2017;6(2)386-391. doi: [Article] [Crossref] 
05. Javalkar SR, Aras RY. A study on complementary feeding practices among mothers in urban and rural areas. Int $\mathrm{J}$ Comm Med Public Health. 2018;5(3)1162-1166.

doi: [Article] [Crossref]

06. Rao S, Swathi PM, Unnikrishnan B, Hegde A. Study of complementary feeding practices among mothers of children aged six months to two years - A study from coastal south India. AMJ. 2011;4(5)252-257.

doi: [Article] [Crossref]
07. Yadav R, Singh P. Knowledge attitude and practices of mothers about breast-feeding in Bihar. Indian J Comm Med. 2004;29(3)130-131. 8 [Crossref]

08. Dhami MV, Ogbo FA, Osuagwu UL, Agho KE. Prevalence and factors associated with complementary feeding practices among children aged 6-23 months in India- a regional analysis. BMC Public Health. 2019;19;1034. doi: [Article] [Crossref] 